University of Wollongong

Research Online

Faculty of Engineering - Papers (Archive)

Faculty of Engineering and Information

Sciences

$1-1-2007$

\title{
Texture and boundary characteristics of severely deformed and recrystallized copper
}

\author{
C. H. J. Davies \\ Monash University \\ W. Q. Cao \\ Monash University \\ C. F. Gu \\ Monash University \\ R. Y. Lapovok \\ Monash University \\ E V. Pereloma \\ University of Wollongong, elenap@uow.edu.au
}

Follow this and additional works at: https://ro.uow.edu.au/engpapers

Part of the Engineering Commons

https://ro.uow.edu.au/engpapers/3285

\section{Recommended Citation}

Davies, C. H. J.; Cao, W. Q.; Gu, C. F.; Lapovok, R. Y.; and Pereloma, E V.: Texture and boundary characteristics of severely deformed and recrystallized copper 2007, 177-182.

https://ro.uow.edu.au/engpapers/3285

Research Online is the open access institutional repository for the University of Wollongong. For further information contact the UOW Library: research-pubs@uow.edu.au 


\title{
Texture and Boundary Characteristics of Severely Deformed and Recrystallized Copper
}

\author{
C. H.J. Davies ${ }^{a}$, W.Q. Cao ${ }^{b}$, C.F. Gu' ${ }^{\text {, R.Y. Lapovok }}{ }^{\text {, }}$, and E.V. Pereloma \\ Department of Materials Engineering, Monash University, VIC, 3800, Australia \\ ${ }^{a}$ Chris.Davies@eng.monash.edu.au, 'Wenquan.Cao@eng.monash.edu.au, \\ cChengfan.Gu@eng.monash.edu.au, 'Rimma.Lapovok@eng.monash.edu.au, \\ eElena.Pereloma@eng.monash.edu.au
}

Keywords: ultrafine grain copper, cryo-rolling, boundary characteristics, EBSD, twinning.

\begin{abstract}
Oxygen-free high conductivity copper was subjected to room temperature equal channel angular extrusion of 8 passes using route Bc. The resulting ultra-fine grain copper was then rolled to thickness reductions of up to $96.5 \%$ at liquid nitrogen temperatures. Annealed coarse grained copper was rolled to the same strain at room temperature for comparison. Samples from the two routes were isochronally and isothermally annealed, and the microstructure and texture evolution studied by electron back scattered diffraction and x-ray diffraction.

The annealing of ultrafine grained copper rolled at liquid nitrogen led to the development of a strong rotated cube texture from a strong Brass texture in the rolled material, rather than the more commonly observed cube texture, which was found in the coarse-grained sample. Accompanying the rotated cube texture was the development of a large fraction of boundaries with rotation angle/axis close to $60^{\circ}<111>$.
\end{abstract}

\section{Introduction}

The annealing of cryo-rolled copper is of interest because it is one method by which ductility can be restored without wholesale degradation of yield strength [i]. However, while annealing could potentially be used to tailor material properties, it is clear that the process has yet to be optimised. The role of twins in the deformation behaviour of ultrafine and nanoscale microstructures has been highlighted as a strengthening mechanism [ii,iii] and the promise of grain boundary engineering via twins [iv] has led to the study of twin formation in severely deformed copper during annealing [v]. It is to the formation of twins during the annealing of severely deformed ultrafine grain materials that we direct our attention.

\section{Experimental procedure}

Ultrafine grain (ufg) copper was produced by equal channel angular extrusion of annealed Oxygenfree high conductivity copper through 8 passes (route Bc) with back pressure of 25MPa, a forward speed of $2 \mathrm{~mm} / \mathrm{s}$ and colloidal graphite as lubricant. After ECAE the grain size of the ufg copper was about $0.25 \mu \mathrm{m}$. Both the ufg copper and the original coarse grained (cg) copper were cold rolled to 96.5\% thickness reduction, the ufg copper at liquid nitrogen temperature (LNT) and the cg copper at room temperature (RT)

The annealing response of the deformed materials was studied by isochronal annealing for five minutes at temperatures between $100^{\circ} \mathrm{C}$ and $220^{\circ} \mathrm{C}$, by isothermal annealing at $180^{\circ} \mathrm{C}$, and by differential scanning calorimetry.

The microstructure and microtexture of the deformed materials and a restricted few recrystallized samples was characterised by electron backscattered diffraction (EBSD). In each case the RD-ND 
sections of the samples were ground, electro-polished and scanned in a Leo-1350 FEGSEM equipped with Nordlys detector and HKL Channel 5 software. Boundary characteristics were determined in the sample and crystal reference frame. Additional analysis was performed using VMAP software. The bulk texture of the samples was determined using an MMA texture goniometer equipped with $\mathrm{Cu}$ anode and a polycapillary beam enhancer. In this case, RD-TD sections were examined. Partial pole figures were obtained on the $\{111\},\{200\}$ and $\{220\}$ planes up to maximum tilt of $80^{\circ}$ with a $5^{\circ}$ interval. The orientation distribution functions (ODFs) were calculated using commercial analytical software developed by ResMat Corp. Post processing was performed using functions written in Matlab.

\section{Results}

The initial texture of the ufg copper rolled at liquid nitrogen temperatures contained a strong brass component, while the texture of the coarse grained copper rolled at room-temperature was more typical of the metal (Figure 1).

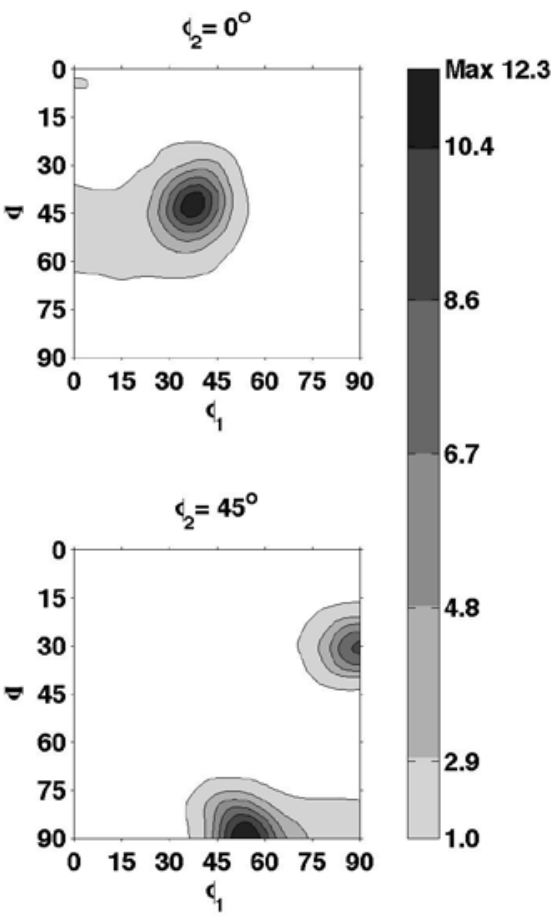

(a)

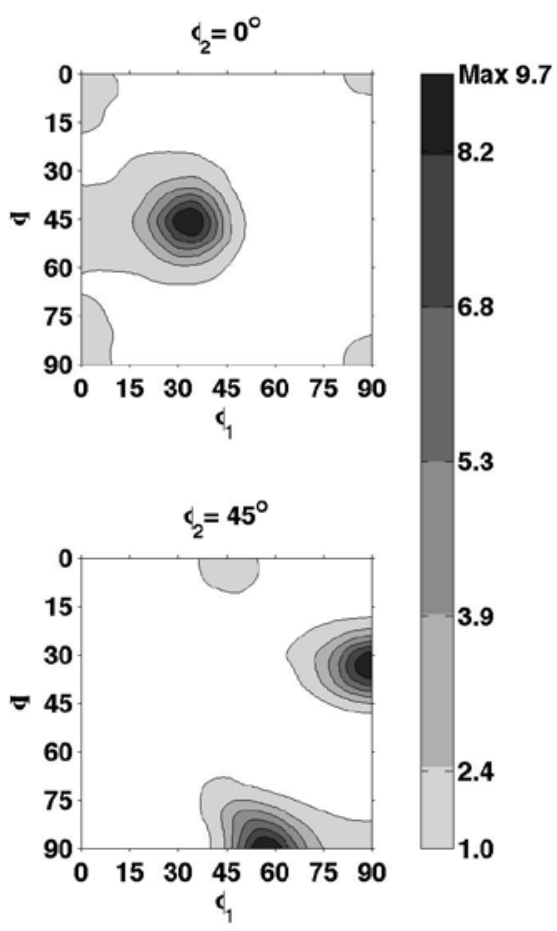

(b)

Figure 1: Initial texture of (a) ufg-LNT and (b) cg-RT.

While the $c g-R T$ sample was found to contain $8 \%$ of grains within $10^{\circ}$ of the brass orientation, the ufg-LNT sample contained 22\% of such grains. Copper and S texture components were higher in the $c g-R T$ sample than in the $u f g-L N T$. Around $38 \%$ of all boundaries in the $c g-R T$ sample were found to be high angle boundaries based on a $15^{\circ}$ lower limit, whereas $62 \%$ of boundaries in the ufg-LNT sample were high angle.

Isochronal annealing. Isochronal annealing of samples of the $u f g-L N T$ material led to rapid recrystallization between $100^{\circ}$ and $156^{\circ} \mathrm{C}$, without much evidence of recovery at the lower temperatures (Figure 2). The same cannot be said of the $c g-R T$ samples, which showed a modest decline in hardness between $130^{\circ} \mathrm{C}$ and $172^{\circ} \mathrm{C}$ before recrystallization was clearly evident. Evidence of abnormal grain growth was apparent in the hardness results for the ufg-LNT samples. The texture of the ufg-LNT material evolved from the as-deformed texture to a strong rotated cube texture 
(Figure 3). At intermediate temperatures twin orientations were evident as twinned Cube (at Euler angles of 45, 70, 45), twinned Goss (at 70, 45, 0 or 90, 19, 45), and twinned Brass (at 74, 45, 0).

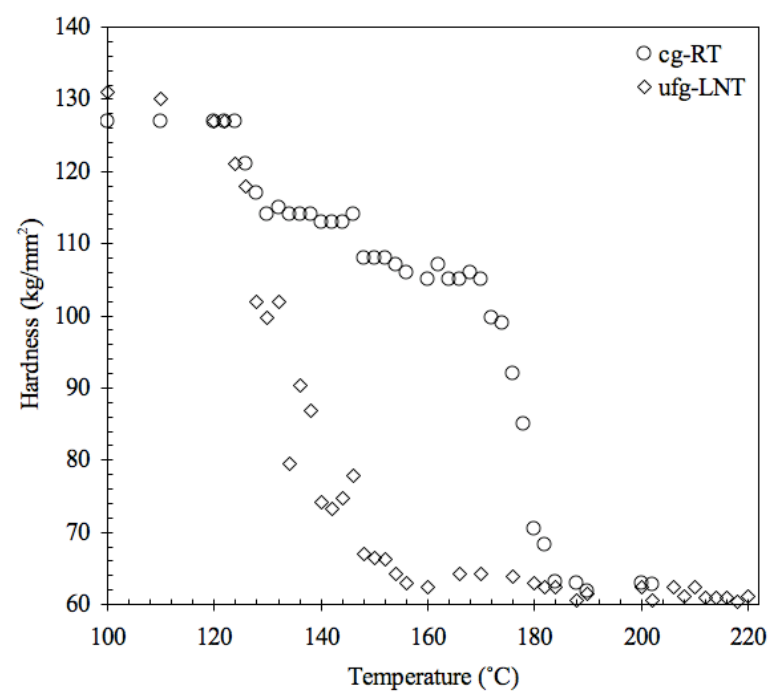

Figure 2: Isochronal recrystallization of rolled samples. Samples annealed for five minutes at each temperature.
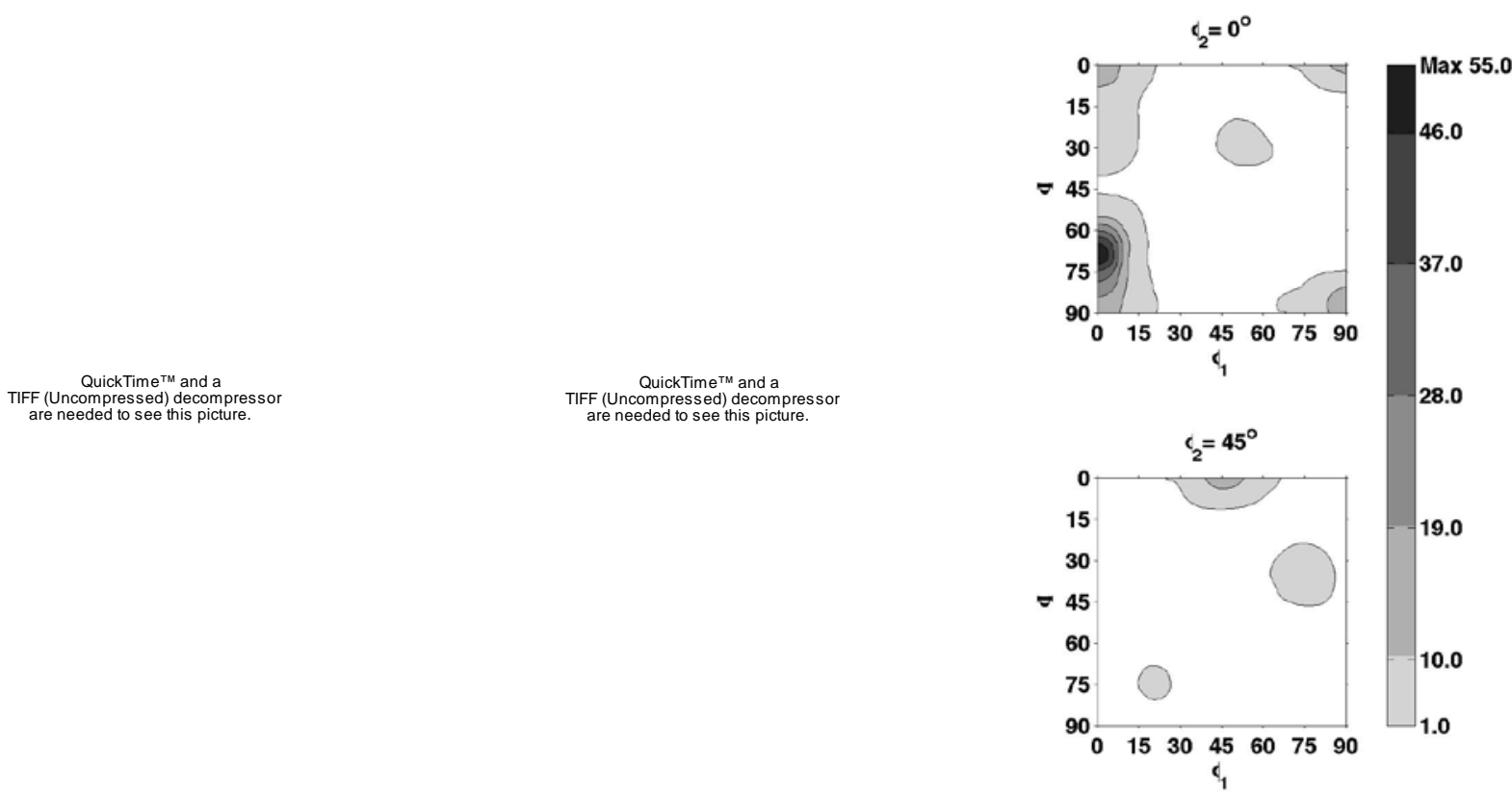

(a)

(b)

(c)

Figure 3: ODFs of $u f g-L N T$ samples annealed for 5 minutes at (a) $120^{\circ} \mathrm{C}$; (b) $150^{\circ} \mathrm{C}$; (c) $202^{\circ} \mathrm{C}$.

Isothermal annealing The time to achieve partial recrystallization was based on averaged microhardness measurements, but as noted above, abnormal grain growth was observed, and this somewhat confounds any quantitative analysis of single EBSD maps. However, in the ufg-LNT sample, many of the special boundaries appear as part of the grain boundary network, rather than as distinct parallel pairs of twin boundaries as is more the case in the $c g-R T$ sample at the current stage of recrystallization (Figure 4).

It is predominantly the alignment of the low angle boundaries and boundaries with misorientation greater than $55^{\circ}$ that changes (Figure 5) after partial recrystallization at $180^{\circ} \mathrm{C}$ of the $u f g-L N T$ and $c g-R T$ samples. In the as-rolled $u f g-L N T$ copper we observe a strong alignment of boundary rotation axes with the rolling direction up to a misorientation of $45^{\circ}$, above which the rotation axes of some boundaries are oriented towards TD. Taking into consideration the lamellar nature of the grains and 
their orientation with the rolling direction, these boundaries are likely to be of tilt character, with the rotation axis in the boundary plane. Alignment of the boundary rotation axes is not nearly so marked in the as-rolled $c g$ - $R T$ sample (Figure 6). After recrystallization, the proportion of grains with low angle boundaries has diminished and their rotation axes have become more spread within the sample reference frame (compare Figures 5a and 5c). In the medium misorientation range, although the spread of rotation axes has become more diffuse, the alignment with the rolling direction is still evident. However, it is for boundary misorientations greater than $55^{\circ}$ that the most striking change has occurred, with the characteristics of non-crystallographic boundaries replaced by an alignment of the boundary rotation axes with the poles of the $\{111\}$ planes for the rotated cube texture in the case of $u f g-L N T$, and cube texture for $c g-R T$. Although the effect appears diminished in the $c g-R T$ compared to the $u f g-L N T$, there is not enough evidence to make definitive statements, and further study is required.

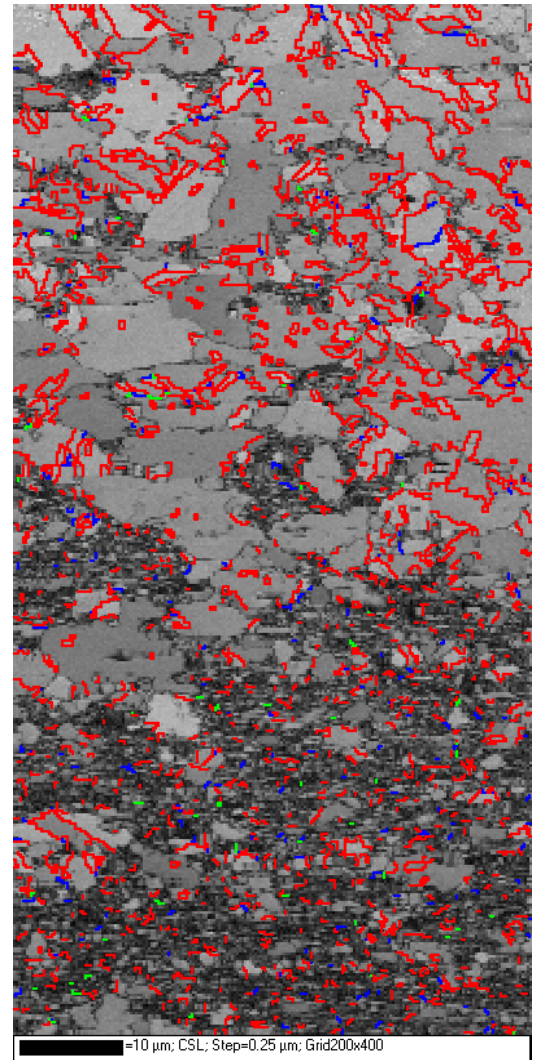

(a)

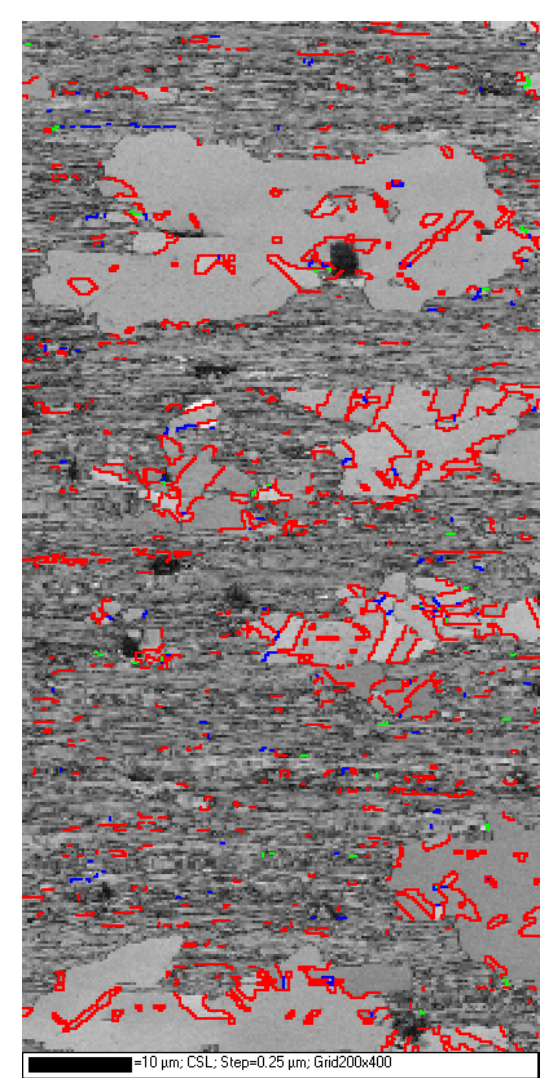

(b)

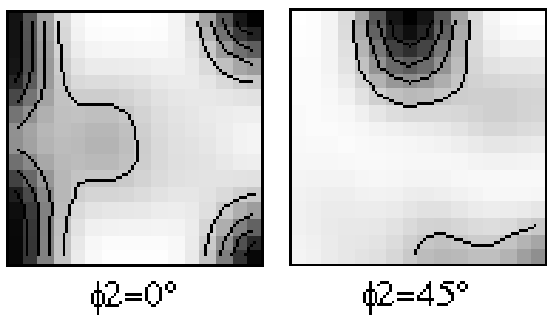

(c)
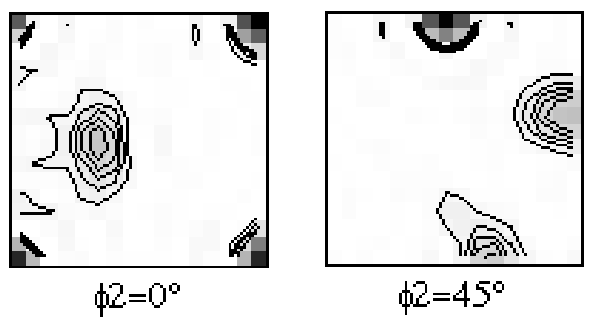

(d)

Figure 4: Boundary character map overlayed on band contrast image of partially annealed (a) ufg$L N T$ sample (b) $c g-R T$. ODF sections of partially annealed (c) $u f g-L N T$ (d) $c g-R T$. In (a) and (b): $\Sigma 3$ boundaries are red; $\Sigma 9$, blue; and $\Sigma 27$, green. In (c) and (d) contours are 1, 2, 3, 4, 5 mrd.

After partial recrystallization, the proportion of boundaries which were $\Sigma 3^{\mathrm{n}}$ in character remained about the same in the $c g$-RT sample, but increased dramatically in the $u f g-L N T$ sample (Table 1). A manual identification of the microtexture of grains with $\Sigma 3$ boundaries revealed that these boundaries were mostly associated with the rotated cube component of the texture. Coupled with the evidence that many of these boundaries form part of the grain boundary network, we can speculate that these might be the result of $\Sigma 3$ regeneration [iv]. 
Table 1: Proportions of special boundaries in rolled and annealed samples.

\begin{tabular}{|l|c|c|c|c|}
\hline \multirow{2}{*}{ Sample ID } & \multicolumn{2}{|c|}{$\begin{array}{c}\text { Special boundaries in rolled material } \\
\text { (\%) }\end{array}$} & \multicolumn{2}{c|}{$\begin{array}{c}\text { Special boundaries in partially } \\
\text { recrystallized material (\%) }\end{array}$} \\
\cline { 2 - 5 } & $\Sigma 3$ & $\Sigma 9$ & $\Sigma 3$ & $\Sigma 9$ \\
\hline$c g-R T$ & 4.7 & 0.7 & 5.9 & 0.5 \\
\hline ufg-LNT & 4.6 & 0.5 & 18.5 & 1.6 \\
\hline
\end{tabular}

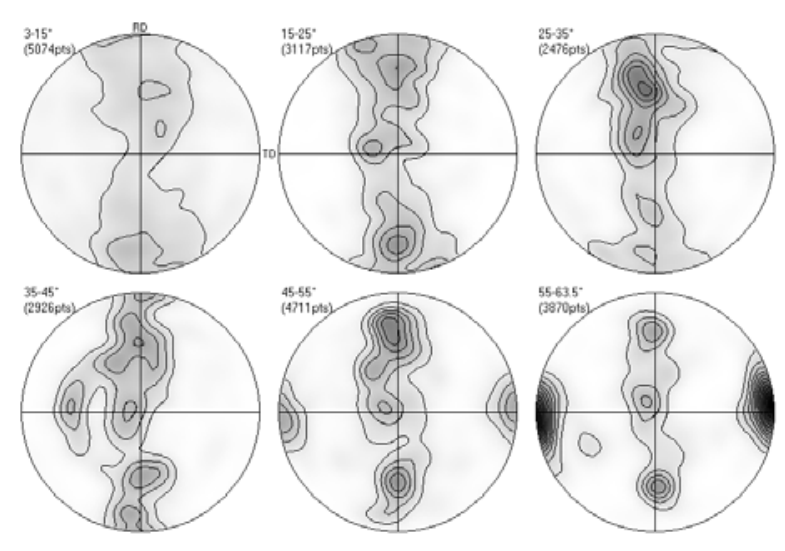

(a)

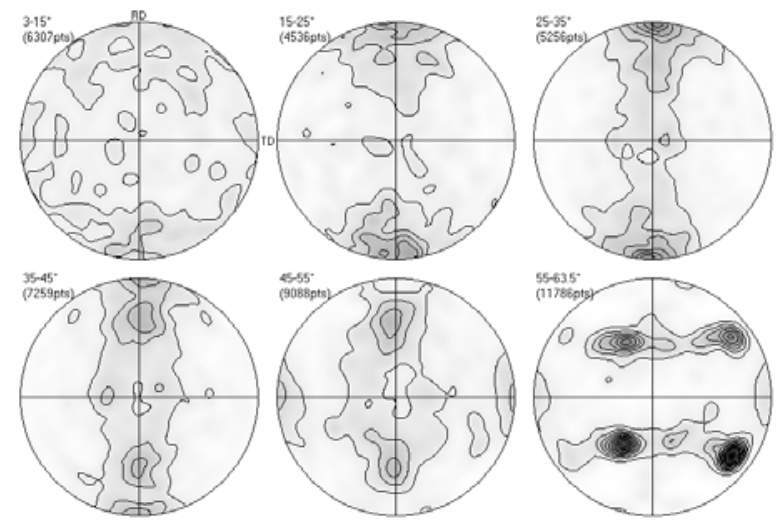

(c)

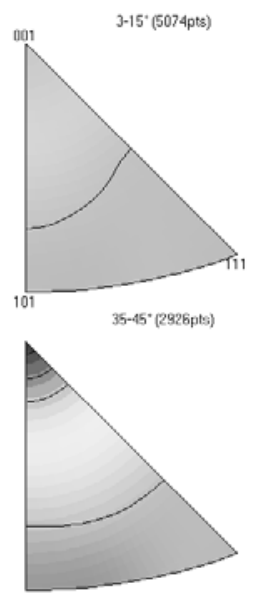

$3-15^{\circ}(6307 \mathrm{pts})$
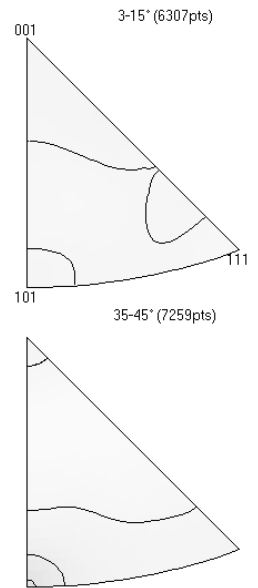
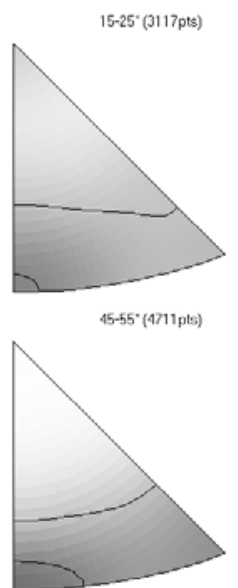

(b)

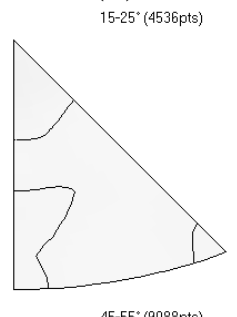

$45^{\circ-55^{\circ}(9088 \mathrm{pts})}$
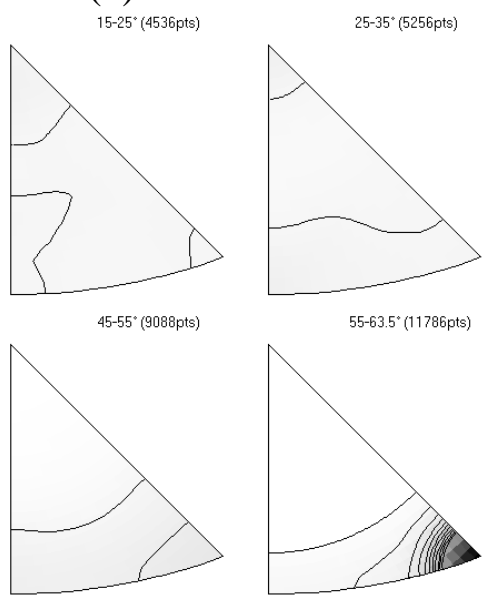

(d)

Figure 5: Boundary rotation axis characteristics in the sample reference frame (a and c) and the crystal reference frame (b and d) classified by misorientation angle for the ufg-LNT sample: asrolled ( $\mathrm{a}$ and $\mathrm{b}$ ), and partially recrystallized (c and d).

\section{Conclusions}

The annealing of ultrafine grained copper rolled at liquid nitrogen led to the development of a strong rotated cube texture, rather than the more commonly observed cube texture. Accompanying this was the development of a significant increase in the fraction of $\Sigma 3$ boundaries. 


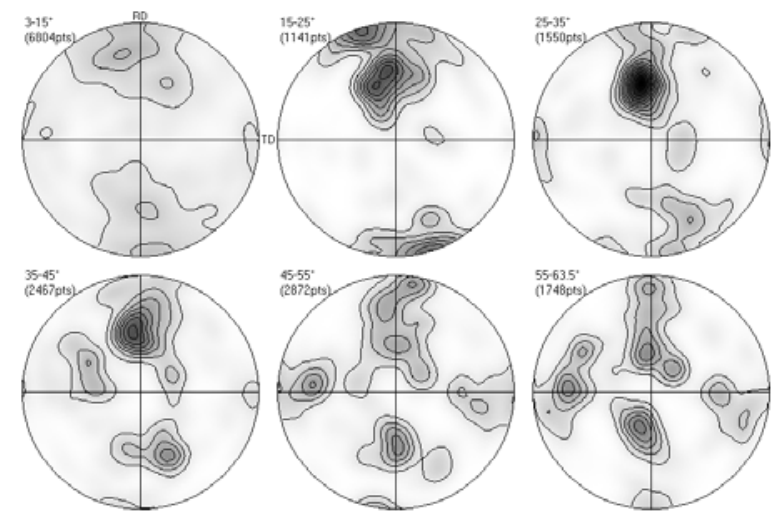

(a)

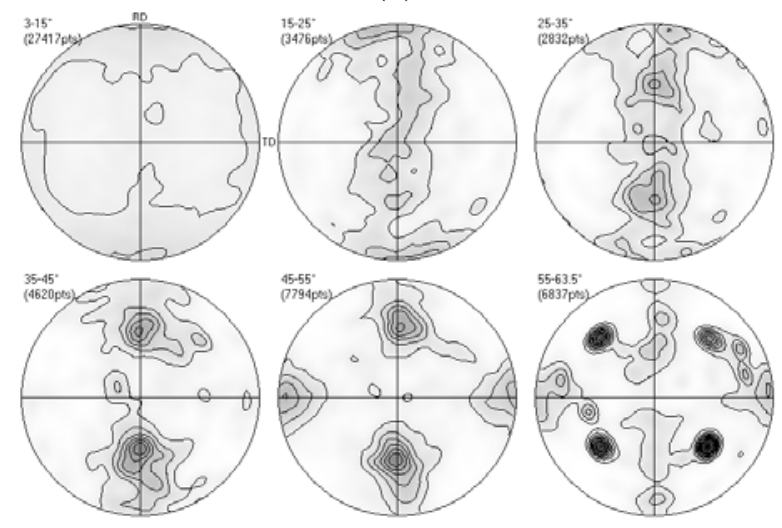

(c)
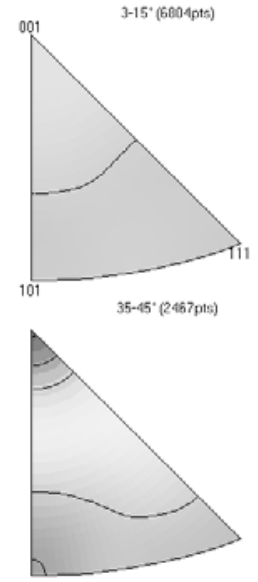

$3-15^{*}(27417 \mathrm{pss})$
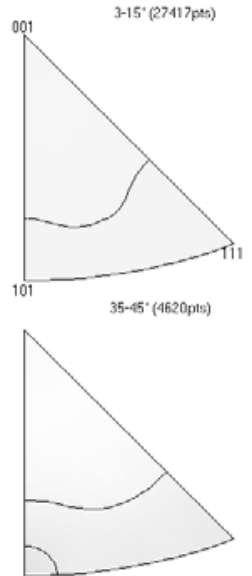
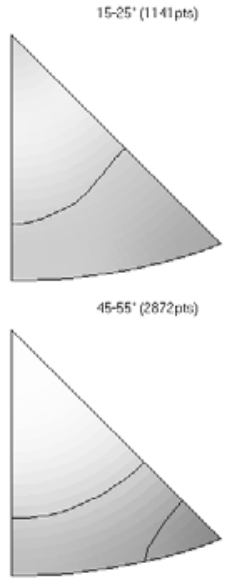

(b)
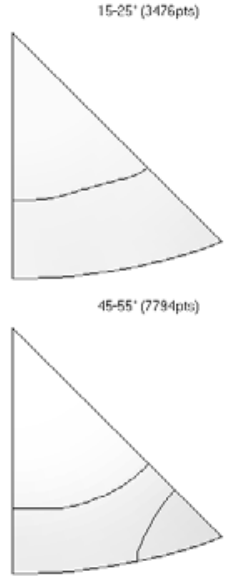

(d)

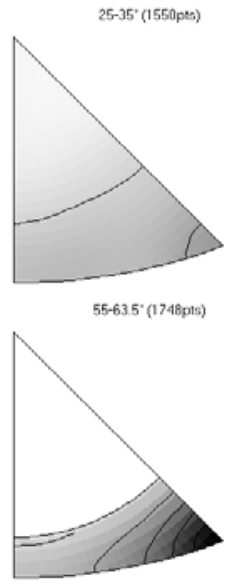

$25-35^{\circ}(2032 \mathrm{pes})$
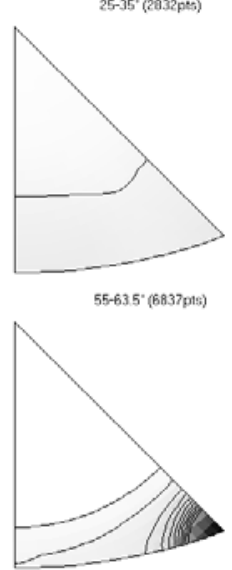

crystal reference frame (b and d) classified by misorientation angle for the $c g-R T$ sample: as-rolled (a and b), and partially recrystallized (c and d).

\section{Acknowledgements}

This work was performed under the auspices of ARC Discovery Project 0557255. VMAP was used courtesy of Professor F.J. Humphreys of the Manchester Materials Science Centre, UK.

\section{References}

[i] Y. Wang, E. Ma: Acta mater., Vol 52 (2004), 1699-1709.

[ii] E. Ma: JoM, Vol 58, Apr (2006), 59-54.

[iii] W.S. Zhao, N.R. Tao, J.Y. Guo, Q.H. Lu, K. Lu: Scripta mater., Vol 53 (2005), 745-749.

[iv] V. Randle, G. Owen: Acta mater., Vol. 54 (2006), 1777-1783.

[v] D.P. Field, R.C. Eames, and T.M. Lillo, Scripta mater., Vol. 54 (2006), 983-986. 